\title{
Hypoxemia in sequential one lung ventilation: oxygen saturation tends to decrease in the second half rather than in the first half of ventilation
}

T. Fukushima ${ }^{1}$, M. Takada ${ }^{1}$, H. Yamamoto ${ }^{1}$

Background and Goal of this study

- Sequential one lung ventilation(OLV) is uncommon, and there are few reports of it to date.

- At our institution, we perform atrial fibrillation treatment surgery (i.e. port-access thoracoscopic radio frequency ablation for pulmonary vein isolation and left atrial appendix amputation)

- This surgery requires sequential OLV(shown below.)

- We have experienced hundreds of cases of sequential OLV and hypothesized that maintaining oxygenation is more difficult in the second half of the procedure than in the first half.

The goal of this study was to examine hypoxemia in sequential OLV retrospectively.
${ }^{1}$ Tokyo Metropolitan Tama Medical Center - Tokyo (Japan)

Materials and Methods

- Retrospective study

- Date:From March 1, 2012 to March 31, 2017

- Inclusion:Patients who underwent atrial fibrillation surgery with sequential OLV

- Exclusion: Usage of Cardiopulmonary bypass. Lack of records.

- How to evaluate hypoxia:

hypoxia time

- defined as the period with an $\mathrm{SpO}_{2} \leqq 95 \%, 92 \%$ and $89 \%$.

This study was approved by the Tokyo Metropolitan Tama Medical Center's Institutional Review Board 29-65.
Atrial fibrillation treatment surgery in our hospital

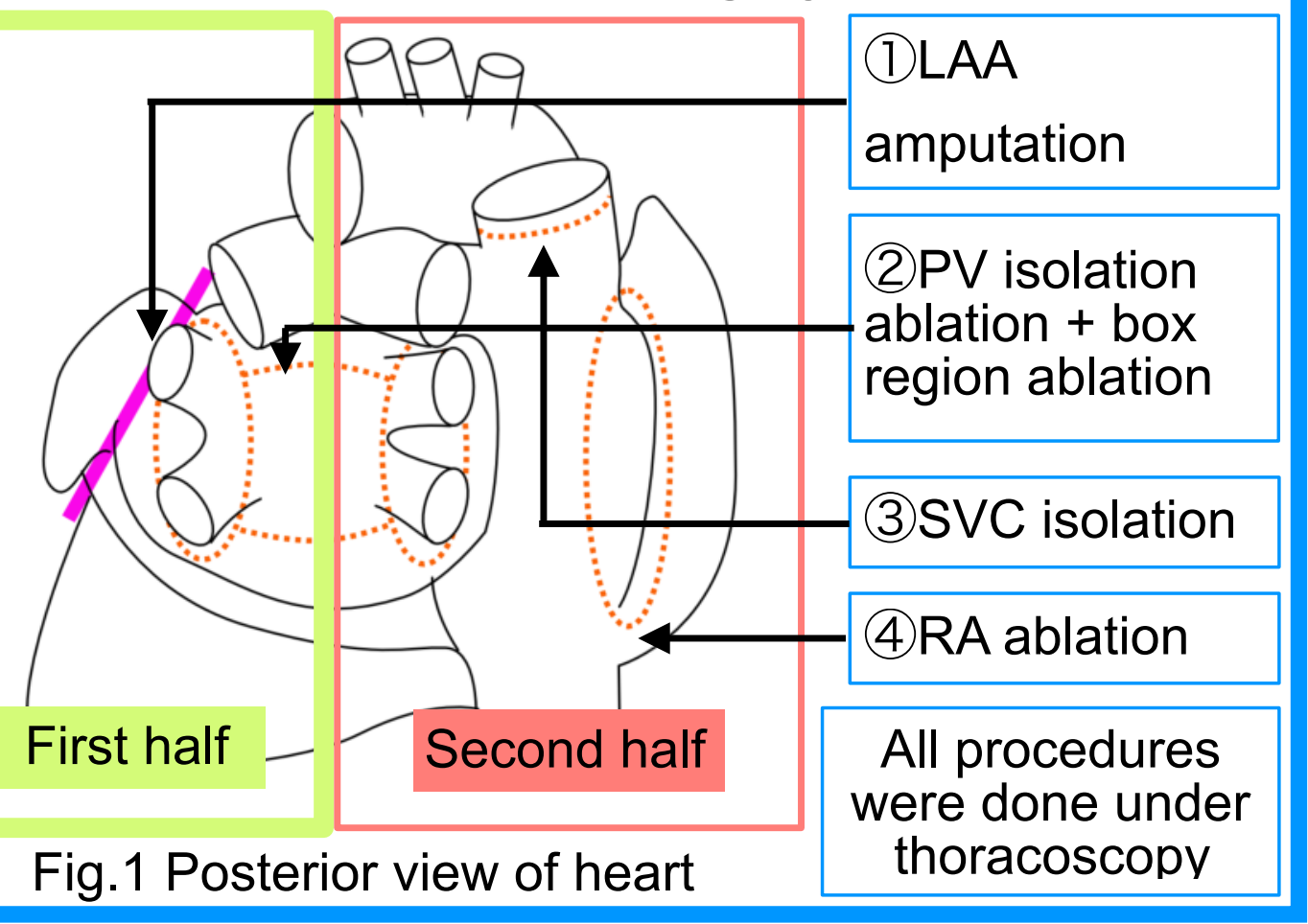

\section{Results and Discussion}

- Patients: 199 patients were included(Table 1)

- The duration of OLV in first half is longer than in second half.( $56 \mathrm{~min}$ vs 39min)

- Hypoxemia time $\left(\mathrm{SpO}_{2} \leqq 95 \%, 92 \%, 89 \%\right)$ is shown Fig. 3.

- Although the duration of the OLV in the first half was longer than in the second half, hypoxemia time in the second half was longer than in the first half.

- Hypoxemia may have occurred more frequently in the second half than in the first half.

Table 1 Characteristics of patients

\begin{tabular}{lrccc}
\hline & mean & s.d. & max. & min. \\
\hline age[y.o.] & 66.1 & 8.8 & 83 & 26 \\
sex & \multicolumn{4}{c}{ male $\mathrm{n}=156 /$ female $\mathrm{n}=43$} \\
BMI[kg/m²] & 23.7 & 3.4 & 35.6 & 16.2 \\
ASA PS & $\mathrm{PS} 2$ & $\mathrm{n}=175 /$ & $\mathrm{PS} 3 \mathrm{n}=24$ & \\
duration of operation[min] & 114 & 34 & 242 & 50 \\
\hline First OLV & & & & \\
duration[min] & 56 & 26 & 191 & 24 \\
minimam SpO $[\%]$ & 92.7 & 5.9 & 100 & 53 \\
\hline Second OLV & & & & \\
duration[min] & 39 & 14 & 104 & 9 \\
minimam SpO $[\%]$ & 89.2 & 6.1 & 100 & 67 \\
\hline
\end{tabular}

\section{Sequential OLV in our Atrial fibrillation surgery}

All sequential OLV was done as below. Patient position was supine.

\begin{tabular}{llcc}
\hline & First half & interval(about 5min) & Second half \\
\hline Right lung & Ventilated & Expanded & Collapsed \\
Left lung & Collapsed & Expanded & Ventilated \\
\hline $\begin{array}{l}\text { Anterior } \\
\text { view of lung }\end{array}$ &
\end{tabular}

Fig.2 Sequential OLV procedure in atrial fibrillation surgery
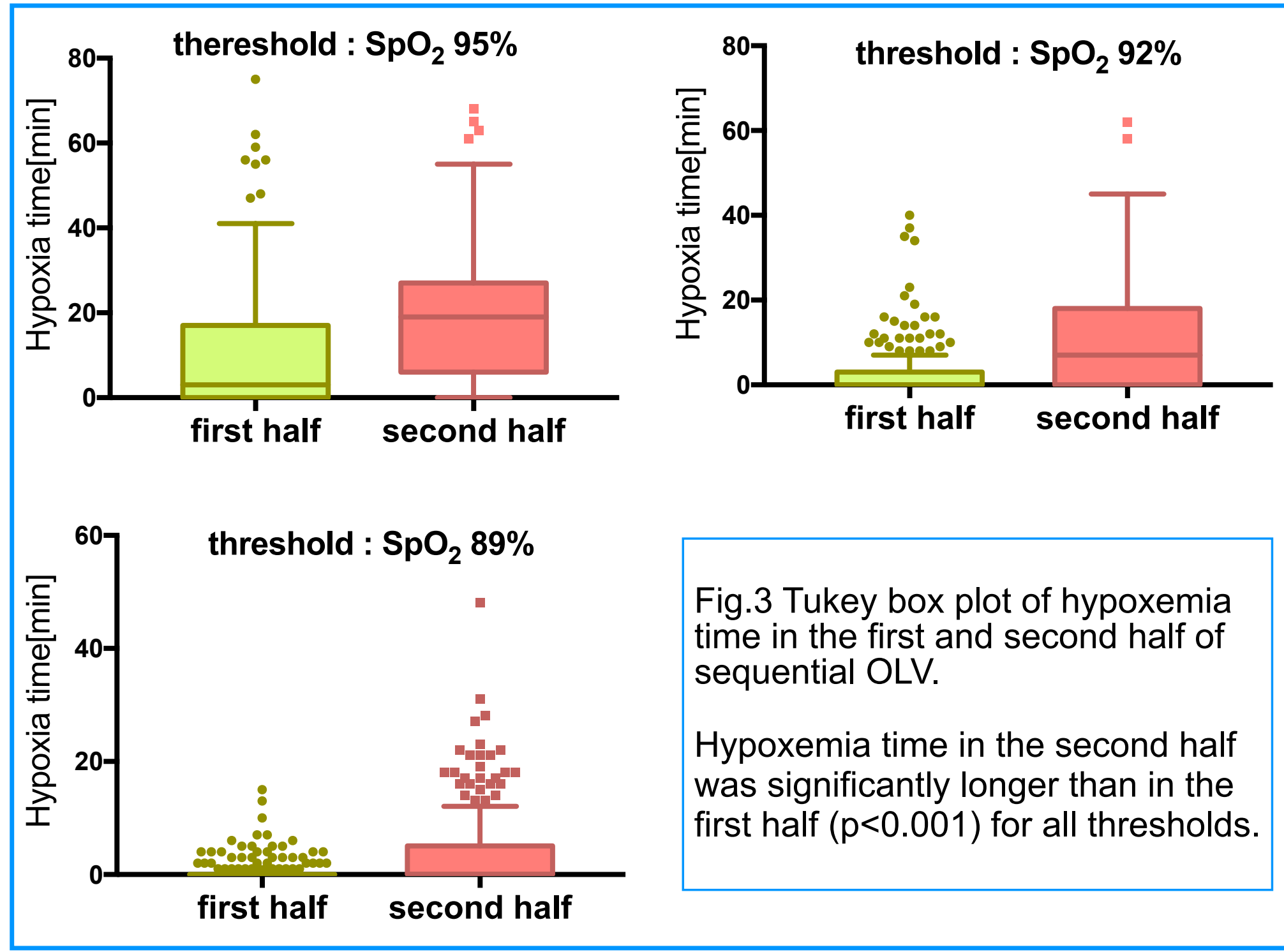

Fig.3 Tukey box plot of hypoxemia time in the first and second half of sequential OLV.

Hypoxemia time in the second half was significantly longer than in the first half $(p<0.001)$ for all thresholds.

In sequential OLV, hypoxemia tends to occur in the second half rather than in the first half. 